\title{
Direct trocar entry for laparoscopy safety and efficiency
}

\author{
Serap Ulusoy, ${ }^{1}$ (1) Mehmet Özer, ${ }^{1}$ (1) İbrahim Kılınç, ${ }^{1}$ (1) Ömer Parlak² \\ 'Department of General Surgery, Atatürk Traininig and Research Hospital, Ankara, Turkey \\ ${ }^{2}$ Department of General Surgery, Yıldırım Beyazıt University Faculty of Medicine, Ankara, Turkey
}

\begin{abstract}
Introduction: This study is an examination of the safety and efficiency of the direct trocar entry method used to create pneumoperitoneum in laparoscopic surgery.

Materials and Methods: Between January 1, 2009 and December 31, 2014, our clinic retrospectively evaluated cases in which a direct trocar entry method was used to create pneumoperitoneum in laparoscopic surgery. The results were compared with those reported in the literature in terms of reliability and efficiency.

Results: Of a total of 1200 patients who underwent laparoscopic surgery, 1152 patients were included in this study due to exclusion for a history of abdominal surgery and risks of adhesion. Among the 1152 patients, 50 had to be removed from the study as a result of unsuccessful entry using the direct trocar method due to the patient's obesity factor. In 4 patients of the 1102, there was under skin hematoma and ecchymosis (bruising of the skin), and 1 had bleeding in the omentum. The laparoscopic procedure on this patient had to be terminated due to the bleeding in the omentum. There were no other complications seen in the study group.
\end{abstract}

Conclusion: A laparoscopic procedure using the direct trocar method is safe and efficient for patients who have no history of abdominal surgery.

Keywords: Direct trocar entry; laparoscopy; pneumoperitoneum.

\section{Introduction}

The objective of this study is to search the safety and efficiency of direct trocar entry method used to create pneumoperitoneum in laparoscopic surgery.

\section{Materials and Methods}

Laparoscopic operations which were performed in our clinic between January $1^{\text {st }} 2009$ and December $31^{\text {st }} 2014$ were evaluated at this study. Only the patients who un- derwent the pneumoperitoneum procedure using the direct trocar method were included in this study. Following the $1-1.5 \mathrm{~cm}$ incisions made under the umbilicus, the abdominal wall was hung up by both sides via towel clamps, then a $10-15 \mathrm{~mm}$ trocar was directly inserted into the abdomen. After checking if a correct entry was made into the abdomen using a laparoscopic telescope, a gas connection was made and the pneumoperitoneum was formed. In terms of arising complications and the need turn into open surgery in patients was compared with literature. 
Since our clinic never used the Veress needle to create pneumperitoneum it was only compared with literature in this respect only.

\section{Results}

Laparoscopic pneumoperitoneum was made for 1200 patients in our clinic during the incisions in dates stated previously. 48 of these patients excluded from study because they previously had the abdominal surgery which is upper and lower abdominal regions that gave a risk of adhesion. The direct trocar entry method was applied to 1152 patients who were included our study. 1102 patients

\section{Table 1. Patients with pneumoperitoneum}

\begin{tabular}{lc} 
& $\mathbf{n}$ \\
\hline Cholelithiasis & 1054 \\
Colorektal cancer & 4 \\
İncisional hernia & 36 \\
İntra-abdominal mesenteric cyst & 1 \\
Trans abdominal preperitoneal repair & 2 \\
Elective appendicitis & 5 \\
Acute cholecystitis & 30 \\
Acut appendicitis & 18 \\
Diagnostic laparoscopy & 2 \\
Total & 1152 \\
\end{tabular}

Table 2. Complications and numbers seen

\begin{tabular}{ll} 
& $\mathbf{n}$ \\
\hline Hematoma/Ecchymosis & 4 \\
Bleeding of omentum & 1 \\
Inability to get into the abdomen & \\
with direct trocars & 50 \\
Total & 55 \\
\hline
\end{tabular}

Table 3. Demographic characteristics of complicated patients

\begin{tabular}{lccc} 
Gender & Age & BMI & Complication \\
\hline Female & 65 & 32 & Bleeding of omentum \\
Female & 58 & 35 & Hematoma/Ecchymosis \\
Female & 35 & 24 & Hematoma/Ecchymosis \\
Female & 62 & 28 & Hematoma/Ecchymosis \\
Male & 73 & 21 & Hematoma/Ecchymosis
\end{tabular}

BMI: Body mass index. of 1152 who underwent with the direct trocar entry method were under elective cases, and 50 were under emergency cases. 642 patients were female and 510 patients were male.Their ages were between 15-92. Performed operations shown at the Table 1.

Organ injury did not occur in any of the cases. 4 patients had under skin hematoma and ecchymosis (bruising of the skin) and 1 had bleeding in the omentum majus. The laparoscopic procedure on this patient had to be stopped due to the bleeding of the omentum. The abdomen was explored laparoscopically. There were no other injuries. Only 50 patients underwent open trocar entry because there was a safety risk with the direct trocar method due to the patients obesity factor. Occured complications shown at Table 2 and demographic characteristics of complicated patients shown at Table 3.

\section{Discussion}

The use of laparoscopy in clinical surgery is extremely common and the number of laparoscopic surgery is increasing with each passing day. Therefore laparoscopic techniques are increasingly gaining importance. As the number of laparoscopic surgeries increase, the techniques, duration, complication, and costs of these operations have also gained importance. In laparoscopic operations, the making of the pneumoperitoneum constitutes as the first step and uses a variety of different techniques. The direct trocar method, Veress needle and open entry methods are the most commonly used techniques in forming the pneumoperitoneum. It is still controversial in which technique is better. There are many studies in literature on this topic. In the study conducted by Agresta ${ }^{[1]}$ and colleagues in 2012 in Italy, had evaluated 2175 patients during 5 years that there were no minor or major complications in the direct trocar entry method and the method was effective and fast. Also in the 2012 in USA a study by Jiang $\mathrm{X},{ }^{[2]}$ stated that the use of the Veress needle increases the risk of minor complications and entry failure, and for this reason prefers the direct trocar entry method. Both studies support our study interms of direct trocar method's safety. In 2012 Bozkurt $^{[3]}$ and colleagues in Turkey conducted a prospective study comparing the efficiency, complication and post surgery pain between the direct trocar entry method and open entry method, and concluded that both techniques have advantages and disadvantages and stated that the surgeons should prefer the technique that they are accustomed to and have experience in. Operation technique that the surgens used 
to do will have been efficient for decrease complications and operations time. Altun ${ }^{[4]}$ and colleagues from Turkey in 2010 investigated the reliability of the direct trocar entry method on laparoscopy; the direct trocar entry method may cause minor complications but was considered a safe and fast method. In 2007 Moberg $^{[5]}$ and colleagues from Sweden investigated the open entry technique in their laparoscopic surgery study and stated that the technique could be used in all patients in a quick an easy way. We preferred open entry technique for 48 pations that have abdominal surgery previously. In 2007 Corcione et al. ${ }^{[6]}$ from Italy emphasized from their study that the open entry technique is safer for patients with history of surgery and they said there are no techniques or methods that don't come without risk. In 2006 Cakir $^{[7]}$ from Turkey emphasized from his study that the Veress needle has not been identified as a component of organ injury and that the Veress needle method is safe. In 2006 Chávez $^{[8]}$ from Mexico reviewed the use of the Veress needle and direct trocar entry method in laparoscopic cholecystectomy; it was seen that the Veress needle method had a higher complication rate and took longer time than the direct trocar entry method. Chávez also emphasized that the direct trocar entry method was a safe, fast and effective method.

In our study we identified that there were no major complications with the patients who underwent with the direct trocar entry method. In total only 5 patients were seen with minor complications. This shows that the direct trocar entry method is both fast and highly reliable. Even though we come across different outcomes from the literature we examined, many shows that there were no serious complications with the direct trocar entry method. Always preferring the open entry technique in terms of complications may be better, but it is obvious that the open entry technique will require a longer period of time and use more carbon dioxide. There is very few works and studies to show how reliable the Veress needle is, and many that show that the Veress needle is less reliable to use. So use of visioport for this patients should be more comfortable.

Open entry technique is reliable to use especially on the patients whose have high body mass index and more abdominal fat but du to the over subcutaneous fat tissue open entry technique with small incision will be harder and operation time will be longer.

As done in our study we have used the direct trocar en- try method on patients who do not have the risk of intraabdominal adhesion and have no history of abdominal surgery and incision, we found the direct trocar entry method reliable and our work is also supported by the literature mentioned above.

\section{Conclusion}

In our study it was found that the direct trocar entry method to be safe and effective for laparoscopic pneumoperitoneum. The literature shows various results in forming the pneumoperitoneum whether it be with the direct trocar entry method, the open entry method, or the Veress needle, and shows no direct correlation between the methods used and complications that arise. The most accurate way to decide on which method to utilize is based on the surgeon's knowledge, experience and the patient's condition.

Peer-review: Externally peer-reviewed.

Conflict of Interest: None declared.

\section{References}

1. Agresta F, Mazzarolo G, Bedin N. Direct trocar insertion for laparoscopy. JSLS 2012;16:255-9. [CrossRef]

2. Jiang $X$, Anderson C, Schnatz PF. The safety of direct trocar versus Veress needle for laparoscopic entry: a meta-analysis of randomized clinical trials. J Laparoendosc Adv Surg Tech A 2012;22:362-70. [CrossRef]

3. Bozkurt M. Comparison of after veres closed trocar and open entry methods in terms of efficiency, complications and postoperative pain in gynecologic laparoscopy: prospective study [Article in Turkish]. JAREM 2012;2:104-8. [CrossRef]

4. Altun H, Banli O, Kavlakoglu B, Kücükkayikci B, Kelesoglu C, Erez N. Comparison between direct trocar and Veress needle insertion in laparoscopic cholecystectomy. J Laparoendosc Adv Surg Tech A 2007;17:709-12. [CrossRef]

5. Moberg AC, Petersson U, Montgomery A. An open access technique to create pneumoperitoneum in laparoscopic surgery. Scand J Surg 2007;96:297-300. [CrossRef]

6. Corcione F, Miranda L, Settembre A, Capasso P, Piccolboni D, Cusano D, et al. Open Veress Assisted technique. Results in 2700 cases. Minerva Chir 2007;62:443-6.

7. Cakir T, Tuney D, Esmaeilzadem S, Aktan AO. Safe Veress needle insertion. J Hepatobiliary Pancreat Surg 2006;13:225-7.

8. Prieto-Díaz-Chávez E, Medina-Chávez JL, González-Ojeda A, Anaya-Prado R, Trujillo-Hernández B, Vásquez C. Direct trocar insertion without pneumoperitoneum and the Veress needle in laparoscopic cholecystectomy: a comparative study. Acta Chir Belg 2006;106:541-4. [CrossRef] 